\title{
Dayside ionospheric convection changes in response to long-period interplanetary Magnetic field oscillations: Determination of the ionospheric phase velocity
}

Article

Published Version

Saunders, M. A., Freeman, M. P., Southwood, D. J., Cowley, S. W. H., Lockwood, M., Samson, J. C., Farrugia, C. J. and Hughes, T. J. (1992) Dayside ionospheric convection changes in response to long-period interplanetary Magnetic field oscillations: Determination of the ionospheric phase velocity. Journal of Geophysical Research, 97 (A12). pp. 19373-19380. ISSN 0148-0227 doi: https://doi.org/10.1029/92JA01383 Available at https://centaur.reading.ac.uk/38829/

It is advisable to refer to the publisher's version if you intend to cite from the work. See Guidance on citing.

Published version at: http://dx.doi.org/10.1029/92JA01383

To link to this article DOI: http://dx.doi.org/10.1029/92JA01383

Publisher: American Geophysical Union

All outputs in CentAUR are protected by Intellectual Property Rights law, including copyright law. Copyright and IPR is retained by the creators or other copyright holders. Terms and conditions for use of this material are defined in the End User Agreement. 


\section{www.reading.ac.uk/centaur}

\section{CentAUR}

Central Archive at the University of Reading

Reading's research outputs online 


\title{
Dayside Ionospheric Convection Changes in Response to Long-Period Interplanetary Magnetic Field Oscillations: Determination of the Ionospheric Phase Velocity
}

\author{
M. A. SAUnders, ${ }^{1}$ M. P. Freeman, ${ }^{1,2}$ D. J. Southwood, ${ }^{1}$ S. W. H. Cowley, ${ }^{1}$ M. LoCKWOOd, ${ }^{3}$ J. C. Samson, ${ }^{4}$ \\ C. J. FARRUGia, ${ }^{5}$ AND T. J. HUGHES ${ }^{6}$
}

\begin{abstract}
Ground magnetic field perturbations recorded by the CANOPUS magnetometer network in the 7 to 13 MLT sector are used to examine how reconfigurations of the dayside polar ionospheric flow take place in response to north-south changes of the IMF. During the 6-hour interval in question IMF $B_{2}$ oscillates between $\pm 7 \mathrm{nT}$ with about a 1-hour period. Corresponding variations in the ground magnetic disturbance are observed which we infer are due to changes in ionospheric flow. Cross correlation of the data obtained from two ground stations at $73.5^{\circ}$ magnetic latitude, but separated by $\sim 2$ hours in MLT, shows that changes in the flow are initiated in the prenoon sector ( 10 MLT) and then spread outward toward dawn and dusk with a phase speed of $\sim 5 \mathrm{~km} \mathrm{~s}^{-1}$ over the longitude range $\sim 8$ to $12 \mathrm{MLT}$, slowing to $\sim 2 \mathrm{~km} \mathrm{~s}^{-1}$ outside this range. Cross correlating the data from these ground stations with IMP 8 IMF $B_{z}$ records produces a MLT variation in the ground response delay relative to the IMF which is compatible with these deduced phase speeds. We interpret these observations in terms of the ionospheric response to the onset, expansion and decay of magnetic reconnection at the dayside magnetopause.
\end{abstract}

\section{INTRODUCTION}

Many observations over the past 25 years demonstrate that the plasma flow in the Earth's high-latitude (polar) ionosphere is driven by coupling between magnetic field lines in the outer magnetosphere and the solar wind. The nature of this coupling, and the ionospheric plasma flows which result, depends strongly on the direction and strength of the interplanetary magnetic field (IMF) [Cowley, 1983; Reiff and Luhmann, 1986; Lockwood and Freeman, 1989]. When the IMF $z$ component is either negative or near zero, the flow is of a twin cell form, with antisunward flow over the polar cap and return sunward flow at lower latitudes in the auroral zones [e.g. Heppner and Maynard, 1987]. Both the spatial extent of these flow cells and the associated flux transport within them increase as IMF $B_{2}$ becomes more negative [Heppner, 1972, 1973; Friis-Christensen and Wilhjelm, 1975; Reiff et al., 1981; Doyle and Burke, 1983; Wygant et al., 1983; Holt et al., 1987, Hairston and Heelis, 1990]. The expansion of the flow cells with negative IMF $B_{z}$ is also reflected in the location of the auroras [Vorobjev et al., 1976; Horwitz and Akasofu, 1977; Holzworth and Meng, 1975, 1984]. This behavior indicates that, as suggested first by Dungey [1961], magnetic reconnection at the dayside magnetopause between the IMF and closed terrestrial flux tubes is the primary coupling mechanism producing polar ionospheric plasma flows. Direct observations at the magnetopause have now confirmed this inference

\footnotetext{
${ }^{1}$ Blackett Laboratory, Imperial College of Science, Technology and Medicine, London, United Kingdom.

${ }^{2}$ Now at Upper Atmospheric Science Division, British Antarctic Survey, Cambridge, United Kingdom.

${ }^{3}$ Rutherford Appleton Laboratory, Chilton, Didcot, Oxfordshire, United Kingdom.

${ }^{4}$ Canadian Network for Space Research, Physics Department, University of Alberta, Edmonton, Alberta, Canada.

SASA Goddard Space Flight Center, Greenbelt, Maryland.

${ }^{6}$ Herzberg Institute of Astrophysics, National Research Council of Canada, Ottawa, Ontario, Canada.
}

Copyright 1992 by the American Geophysical Union.

Paper number $92 \mathrm{JA} 01383$.

0148-0227/92/92JA-01383\$05.00
[Paschmann et al., 1979, 1986; Sonnerup et al. 1981; Rijnbeek et al., 1984; Berchem and Russell, 1984]. However, when IMF $B_{z}$ becomes significantly positive, above $\sim 1$ to $2 \mathrm{nT}$, "reversed" convection cells containing sunward flowing plasma can appear within the polar cap [Maezawa, 1976; McDiarmid et al., 1978a; Burke et al., 1979; Reiff, 1982]. These flows are believed to be driven by reconnection poleward of the cusps between the IMF and open tail lobe field lines [Dungey, 1963; Russell, 1972]; indeed, direct experimental evidence for reconnection at the tail lobe magnetopause has now begun to emerge [Gosling et al., 1991]. In the case of both "normal" and "reverse" flow cells, dawn-dusk asymmetries also occur in the flow. These are directly related to the sense of the IMF BY component [Heppner, 1972; McDiarmid et al., 1978b; Heppner and Maynard, 1987], and result from the dawn-dusk forces exerted on newly opened flux tubes by this component [Jorgensen et al., 1972; Atkinson, 1972; Cowley, 1981] (see also Cowley et al. [1991] and the references therein).

Given the strong response of the dayside polar ionospheric flows to the IMF vector outlined above, and the rapid time variability (periods as short as a few minutes or less) often present in the IMF, questions immediately arise concerning the time scale and the nature of polar ionospheric plasma flow reconfigurations following changes in the MMF. Following the early discussion by Russell [1972], recent studies have emphasized the need to discuss the flow in terms of two time-dependent components which are usually superposed. One component is driven by coupling (principally reconnection) at the dayside magnetopause, while the other is driven by reconnection in the tail [Lockwood and Freeman, 1989; Lockwood et al., 1990; Cowley and Lockwood, 1992]. The high-latitude flows driven by dayside reconnection are strongest on the dayside and are associated with an expanding polar cap, while plasma flows driven by tail reconnection are greatest on the nightside and accompany a contracting polar cap. Quantitative models for these flows have been derived by Siscoe and Huang [1985].

With regard to the time scale for the flow response it is well known that the first of the components, that driven by coupling at the magnetopause, responds rapidly to changes in the IMF on time scales of several minutes, though it may take intervals of 10-15 min for the flow pattern to reconfigure completely [Nishida, 1968a,b; Pellinen et al., 1982; Nishida and Kamide, 1983; McPherron and Manka, 1985; Claver and Kamide, 1985; Rishbeth et al., 1985; Todd 
et al., 1986; Clauer and Friis-Christensen, 1988; Greenwald et al., 1990]. The flow driven by reconnection on the nightside is related principally to instability of the central magnetotail system and to substorms [e.g. Russell and McPherron, 1973; Hones, 1973], and has a more complex response. However, studies of the correlation between IMF $B_{2}$ and magnetic disturbance indices such as $A E$ and $A L$, which emphasize nightside current systems, indicate that these flows respond to IMF $B_{z}$ with about a 40-min time delay [Baker et al., 1981, 1983; Bargatze et al., 1985a,b].

Following a burst of reconnection at the magnetopause or in the central magnetotail, one would expect a twin-vortical plasma flow system to be excited in the two conjugate ionospheres after the appropriate Alfvén wave propagation delay along the field lines. Initially these plasma vortices will be localized near the conjugate reconnection sites but will then expand outwards to fill the whole polar caps [Lockwood et al., 1986; Cowley and Lockwood, 1992]. The speed at which the flow pattern expands and evolves will be determined by a number of factors. These include the time scale for flux tubes to evolve following reconnection (for example, in moving from the dayside to the tail after subsolar reconnection), the expansion of the reconnection $X$ line over the magnetopause following a switch in the sense of the IMF, or across the magnetotail following the onset of a substorm, and the finite speed at which information propagates in the magnetosphere-ionosphere system following the change in magnetospheric boundary conditions. The time scale associated with each of these processes may be simply estimated as about $10 \mathrm{~min}$, this corresponding to characteristic speeds of a few $100 \mathrm{~km} \mathrm{~s}^{-1}$ and to characteristic spatial scales of a few tens of $R_{E}$ [Cowley et al., 1991]. The phase speed with which the flows expand and change at ionospheric heights is thus expected to be $\sim 5 \mathrm{~km} \mathrm{~s}^{-1}$, this corresponding to the above $\sim 10$-min time scale and to the $\sim 3000-\mathrm{km}$ horizontal spatial scale of the vortical flows.

There have, however, been few observations which measure, either directly or indirectly, the expansion speed of a perturbation to the polar ionospheric flow pattern following the onset of magnetopause or tail reconnection. Here we focus on the response to dayside reconnection by examining variations in the dayside flow triggered by changes in IMF $B_{2}$. Two approaches may be taken. The first (indirect) method is to examine the time delay, as a function of position, for ionospheric flows to respond to variations in IMF $B_{z}$. This approach was employed by Etemadi et al. [1988], who performed a cross correlation analysis against IMF $B_{2}$ of dayside flows recorded by the European Incoherent Scatter Radar (EISCAT) "Polar" experiment. They found that for the magnetic latitude range $71^{\circ}$ to $74^{\circ}$ the ionospheric response delay varied with local time from a minimum of $\sim 3 \mathrm{~min}$ in the early postnoon sector to $\sim 10-15$ minutes near to the dawn-dusk meridian. These time delays were calculated from the time at which a particular value of IMF $B_{z}$ is estimated to have been present at the subsolar magnetopause. This increasing delay corresponds to the spread of a new flow pattem away from the noon sector at an average phase speed of $\sim 4 \mathrm{~km} \mathrm{~s}^{-1}$ [Lockwood and Cowley, 1988]. Similar results were derived by Todd et al. [1988] using the same data set as Etemadi et al. [1988], but who instead examined the response of the flow to well-marked southward or northward turnings of the IMF. A notable feature of their results is the similar response time of the flow to southward and northward tumings of the IMF. After a southward turning an enhanced flow appears first near noon and then expands in local time, while following a northward turning a reduction in the flow also appears first near noon, and similarly expands. An altemative and more direct approach to determining flow pattem expansion speeds is to examine the correlation between the flows (or a related ionospheric parameter such as the $F$ region ion temperature) at two adjacent points in the ionosphere. To date, only one such determination has been published for the response to dayside reconnection, that of Lockwood et al. [1986] (see also Lester et al. [1990] for a similar analysis in relation to tail reconnection). These authors examined an ion temperature enhancement seen in the two radar beams of the EISCAT "Polar" experiment, this feature being associated with an abrupt onset of flow in the afternoon sector following a sudden southward turning in the IMF. They found that the temperature enhancement (and by implication the flow enhancement) propagated eastward away from noon across the radar field of view at a speed of $2.6 \mathrm{~km} \mathrm{~s}^{-1}$.

In this paper we use data to examine the temporal response of the dayside polar ionospheric flow to a change in the IMF using both of the approaches described above. Specifically we examine the magnetic field perturbations observed on the high-latitude dayside of the Earth by the CANOPUS ground magnetometer network located in northem Canada. Our data span a 6 hour interval in which the IMF $B_{z}$ component oscillates between $\pm 7 \mathrm{nT}$ with about a 1-hour period. During this interval the east-west or $Y$ component of the ground magnetic field exhibits related oscillations which we infer are due to Hall currents driven by the north-south component of the ionospheric flow. Oscillations of similar amplitude and period are also present in the IMF $B_{Y}$ component and the north-south or $X$ component of the ground magnetic field during the interval but these will not be the major focus of the paper. We concentrate here on the $\boldsymbol{Y}$ component ground magnetic signals as these correlate most strongly with the IMF $B_{z}$ component. We first use the data from two ground stations located at $73.5^{\circ}$ magnetic latitude but separated in

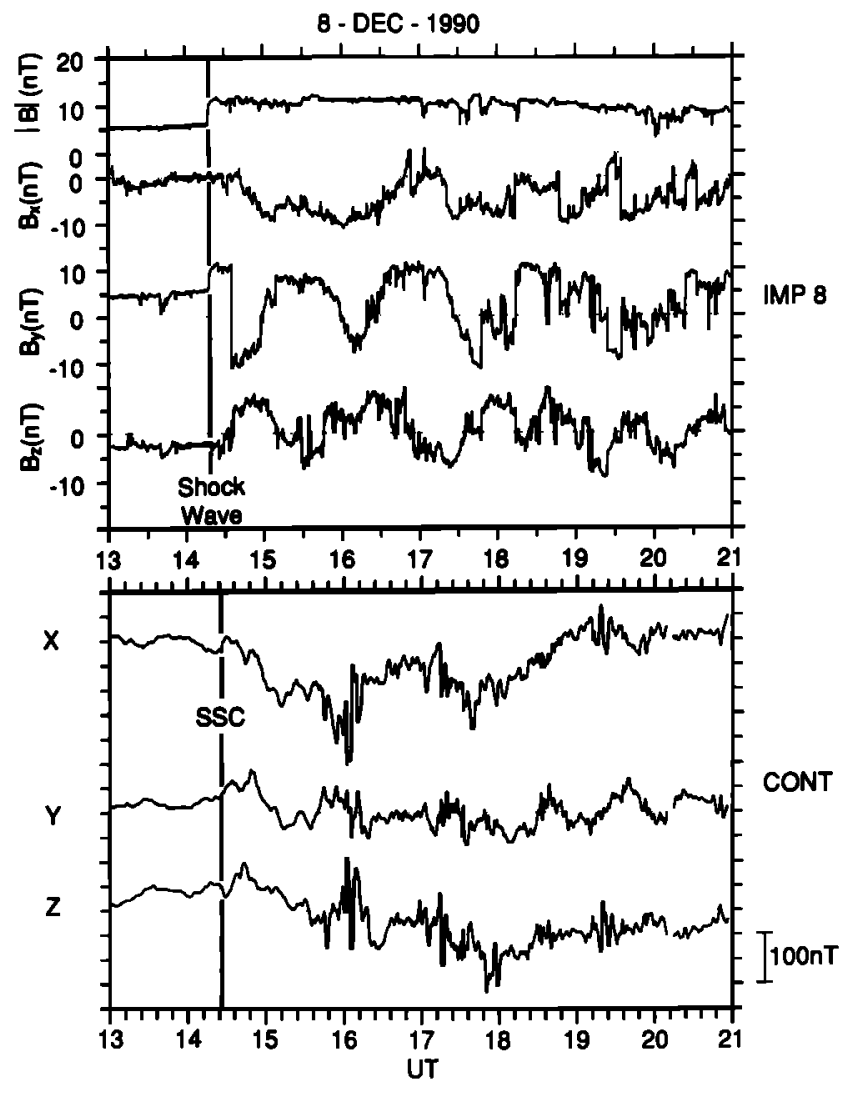

Fig. 1. Comparison of (top) the interplanetary magnetic field and (bottom) the CANOPUS ground magnetometer data for an 8 -hour interval on December 8,1990 . The IMP 8 records are 15 -s averages in GSM coordinates and show the interplanetary shock at 1419 UT and its associated Alfvénic wave train. The CANOPUS records, which consist of $X, Y$ and $Z$ component data from a single station (Contwoyto Lake) at 5-s resolution, show oscillations with a period similar to that seen in space. 
MLT by $\sim 2$ hours to examine the east-west phase propagation of the variations in the $Y$ magnetic field component over the MLT range from 7 to 13 hours. We find that the field variations propagate eastward and westward away from the prenoon sector with a phase speed of $\sim 5 \mathrm{~km} \mathrm{~s}^{-1}$, though with decreasing speed at later local times. Second, we compare the data from these stations with concurrent IMF $B_{\mathbf{2}}$ observations and show that the observed variations in the response delay with MLT are entirely compatible with the east-west phase speeds determined from the two-station comparison.

\section{OBSERVATIONS}

Figure 1 is an overview plot presenting the interplanetary magnetic field and the ground magnetometer data from one of the CANOPUS stations employed in this paper. The data cover the interval from 1300 to 2100 UT on December 8, 1990 (which, incidentally, occurred during the first Earth encounter of the Galileo spacecraft). The upper panel shows the magnitude and components (in GSM coordinates) of the interplanetary field recorded by the IMP 8 satellite, which at the time was located in the solar wind upstream of the Earth nearly on the Earth-Sun line at $(38,3,-2) R_{E}$ in GSE coordinates. The lower panel displays the three components of the geomagnetic disturbance, namely $X$ (geographic north-south, with north positive), $Y$ (geographic east-west, with east positive) and $Z$ (vertical, with positive downward) recorded by the station Contwoyto Lake of the CANOPUS magnetometer network. The horizontal dashed line associated with each component is the mean value of the component on that day. Scaling is given by the 100-nT bar mark on the bottom right.

The field and plasma data from IMP 8 show that an interplanetary shock swept by the satellite at 1419 UT. This shock was recorded on the ground as a storm sudden commencement (ssc) at 1426 UT (Solar Geophysical Data, Part 1, Feb. 1991). The shock and the ssc are indicated in Figure 1 by the heavy vertical lines. The former is associated with an abrupt doubling of the IMF field strength and a change from a steady $+Y,-Z$ pointing magnetic field to one where the magnetic field exhibits large oscillations in direction. These oscillations occur mainly in the $Y$ and $Z$ components where they are
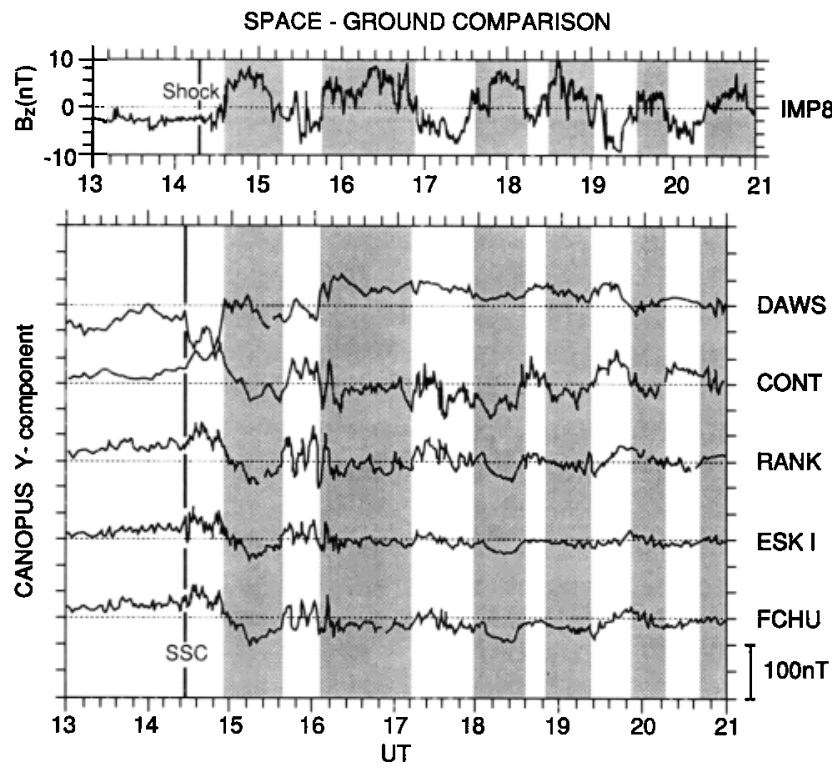

Fig. 2. IMP 8 IMF $B_{z}$ data displayed with the $Y$ component ground magnetometer data from five CANOPUS stations. The antiphase relationship is consistent with reconnection causing the signals seen on the ground. Shading highlights the association of the maxima in IMF $B_{2}$ with the minima in ground BY. in antiphase. Analysis to be reported elsewhere shows that these signals are accompanied by similar perturbations in solar wind plasma velocity and are Alfvén waves propagating toward the Earth in the solar wind frame. The important point for this study, however, is that IMF $B_{z}$ oscillates between about $\pm 7 \mathrm{nT}$ six times during the postshock interval, with a period of $\sim 1$ hour. Related oscillatory magnetic field variations are seen in the Contwoyto Lake (CONT) geomagnetic data. These perturbations are evident in all the components but are clearest in the $Y$ component data where they reach $\sim 100 \mathrm{nT}$ peak-to-peak amplitude. For this reason we focus on this component in our space-ground comparison. Cross correlation of the full IMF and station CONT BY time series indicates that, as expected, it is IMF $B_{z}$ rather than IMF $B Y$ which exerts primary control over the ground $B_{Y}$ signal. The peak correlation between the full (1500 to 2100 UT) IMF $B_{z}$ and CONT $B_{Y}$ time series is 0.40 , while that between the full IMF $B_{Y}$ and CONT $B Y$ time series is just 0.14 . Thus the two parameters of principal interest to our study are IMF $B_{z}$ and CANOPUS $B y$.

Figure 2 presents an overview of the IMF $B_{2}$ and CANOPUS $B_{Y}$ data sets. The top panel displays the IMF $B_{z}$ field recorded by IMP 8 and the lower panels give the $Y$ component of the geomagnetic disturbance recorded by five stations of the CANOPUS network. During the interval in question the CANOPUS network is located in the morning sector rotating from predawn to just past noon. The relative locations of the stations are shown in Figure 3 as a function of geographic latitude and longitude. The five stations whose data are presented in Figure 2 are highlighted: Dawson (DAWS),

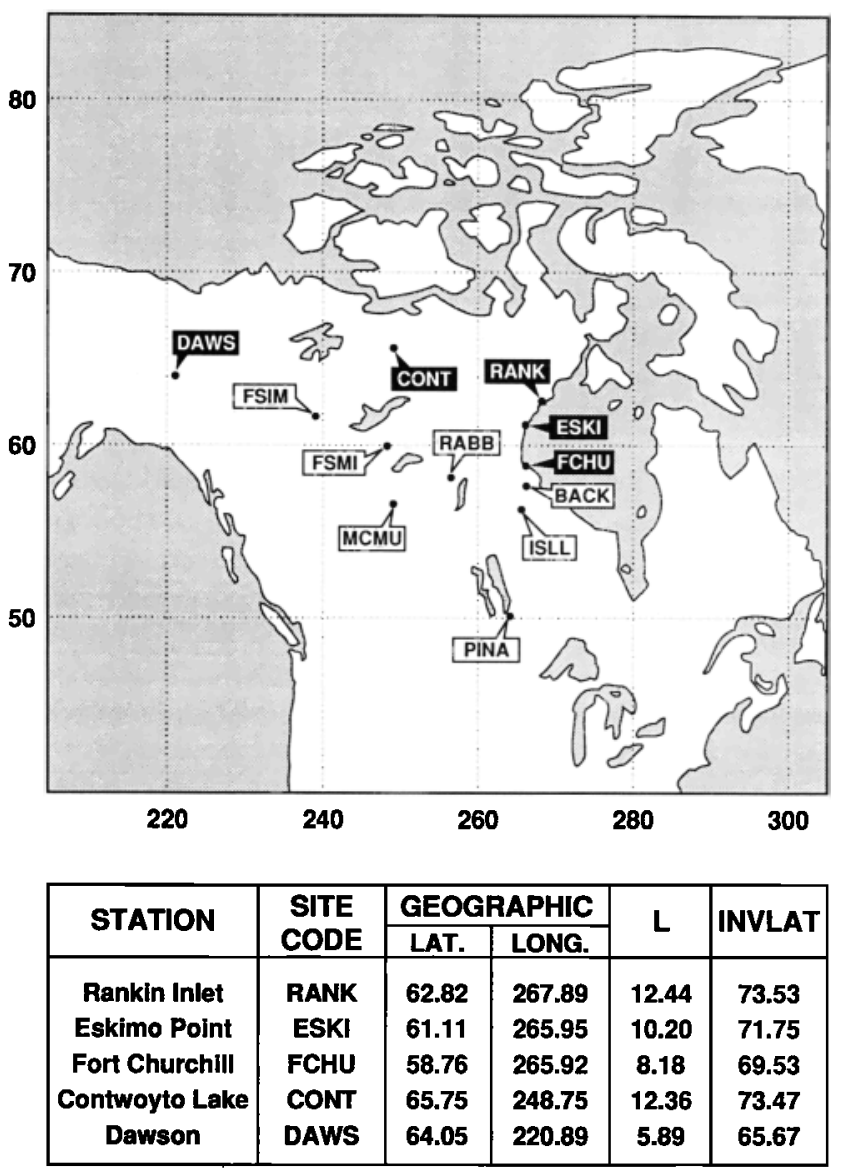

Fig. 3. CANOPUS magnetometer station positions displayed in geographic coordinates. Data from the five stations shown highlighted are used in this paper. 
Contwoyto Lake (CONT), Rankin Inlet (RANK), Eskimo Point (ESKI) and Fort Churchill (FCHU). RANK, ESKI and FCHU form a latitudinal chain $(L=8-13)$ down the west coast of Hudson Bay, while CONT and DAWS are displaced in longitude by 2 hours and 4 hours of magnetic local time at $L$-values of about 12 and nearly 6 respectively. The location of each station, including its magnetic coordinates, is given in the table at the bottom of Figure 3 . As indicated by the shading stripes a clear relationship exists between the space and ground signals in Figure 2. Intervals of negative IMF $B_{z}$ are associated with positive deflections in the CANOPUS data indicating a poleward ionospheric plasma flow. The data also suggest that during intervals of positive IMF $B_{2}$ negative dellections of the field relative to the overall baseline occur, indicating equatorward flow at these times. However, the correct bascline for the ground magnetometer data needed to infer the direction and absolute magnitude of the flow is uncerlain during this disturbed interval, so definite conclusions are difficult to draw. Howcver, the results derived below are independent of any such inferences.

In Figure 2 the CANOPUS data are shown displaced in time relative to IMF $B_{z}$ by $18 \mathrm{~min}$. This is the optimum overall lag computed from cross-correlating the full IMF $B_{z}$ and station CONT $B Y$ time series, and is reliable since the two time series are correlated at greater than a $99 \%$ confidence level (cross correlation coefficient $=0.40$, number of pairs of points $=4679$ [Fisher, 1948]). The 18-min lag compares with an estimated value of $13 \mathrm{~min}$ for changes in the interplanetary field to move from IMP 8 to the noon sector ionosphere. The 13-min figure consists of $\sim 11 \mathrm{~min}$ for IMF changes to move from the satellite to the dayside magnetopause (computed using the algorithm of Etemadi et al. [1988]) with $\sim 2$ $\min$ for propagation to the ionosphere as an Alfvénic disturbance. In making the former estimate, account is taken of the slowed plasma flow speeds in the magnetosheath, using values for the position of the subsolar bow shock $\left(11.9 R_{E}\right)$ and magnetopause $\left(8.8 R_{E}\right)$ based upon the prevailing flow speed $\left(400 \mathrm{~km} \mathrm{~s}^{-1}\right)$ and density $\left(15 \mathrm{~cm}^{-3}\right)$ of the solar wind. The assumptions and uncertainties in this calculation are discussed by Lester et al. [1990].

Examination of the CANOPUS data show that the signals at RANK, ESKI and FCHU, the stations forming the latitude chain, are in phase with each other but there is a slight phase difference between these three sites and the stations CONT and DAWS, which are at different magnetic local times. In the following section we examine in more detail the phase delay between the signals recorded at CONT and RANK, stations situated at corrected invariant latitudes of $73.5^{\circ}$ $(L=12)$ and separated in corrected magnetic longitude by $28^{\circ}$ (nearly two hours of magnetic local time). This will provide information on the east-west phase velocity of the field variation recorded on the ground.

\section{LONGITUDLNAL PHASE MOTION}

Figure 4 shows superposed the CONT (solid line) and RANK (dashed line) $Y$ component traces. The magnetic local times of each station are plotted along the abscissa. These show that during the interval in question the stations rotate with the Earth from near dawn to the early afternoon sector; for example, RANK moves from 5 MLT at 1300 UT to $13 \mathrm{MLT}$ at $2100 \mathrm{UT}$. Although the field variations at each station appear similar, a clear time lag is evident both near the start and, more noticeably, toward the end of the 8-hour interval. However, the sense of the lag changes. In the pre-10 MLT sector the field variations around 1600 UT have RANK leading in phase, while in the post-10 MLT sector the variations around 1930 UT show that CONT now leads in phase. This change in phase is consistent with an expansion of perturbations to the ionospheric flow

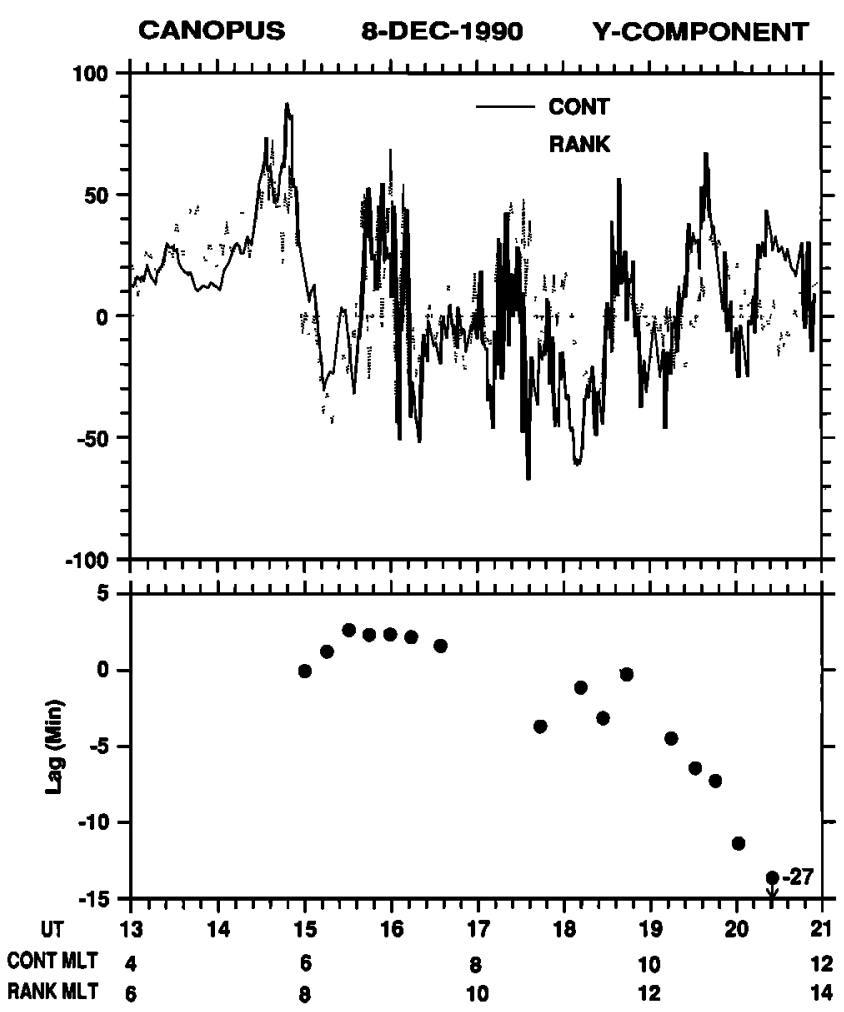

Fig. 4. Superposition of CONT and RANK magnetometer data, as a function of both UT and magnetic local time (MLT). The time delay between the two signals, shown explicitly in the lower panel, indicates phase motion away from about 10 MLT initially at a phase speed of $5 \mathrm{~km} \mathrm{~s}$.

pattern away from $\sim 10$ MLT. The time lag between correlated signals at the two stations is shown explicitly in the lower panel of Figure 4. Cross correlation functions were calculated by cross correlating the two time series using a 1-hour sliding window on data of 5-s resolution. Only lags at the correlation peak and with a correlation coefficient above 0.5 are plotted, these values being significant at greater than the $99 \%$ confidence level. A positive lag indicates that RANK leads in phase while a negative lag implies that CONT is leading. In the postdawn sector, between $\sim 7$ and $9 \mathrm{MLT}$, the lag is $+2.5 \mathrm{~min}$, implying a westward phase speed of $5 \mathrm{~km} \mathrm{~s}^{-1}$ for the disturbance propagation. Similar lags but negative in sign are observed between $\sim 10$ and 11 MLT, indicating eastward phase motion at about the same speed. From 11 to $12 \mathrm{MLT}$, however, the lag increases to $\sim-7.5 \mathrm{~min}$, indicating a slower eastward propagation at $\sim 2 \mathrm{~km} \mathrm{~s}^{-1}$. At later MLTs this speed slows even further.

A similar phase speed is obtained by comparing $D$ component magnetograms from the two U. S. Geological Survey (USGS) stations Barrow and College (data courtesy of the USGS in Boulder, Colorado) situated at nearly the same invariant latitude as the CONT-RANK pair but at a MLT 3 hours earlier. These stations record signals similar to those seen at CONT and RANK, these being particularly clear during the 1800 to 2100 UT interval when College leads Barrow in phase by $4 \mathrm{~min}$ (data not shown). This phase lag corresponds to a tailward phase speed of $3 \mathrm{~km} \mathrm{~s}^{-1}$ at a longitude of about 8 MLT. Thus when the CONT-RANK station pair is seeing duskward phase motion at $11 \mathrm{MLT}$, the Barrow-College station pair observes dawnward motion at $8 \mathrm{MLT}$. This result agrees with our finding that the phase velocity reverses about $10 \mathrm{MLT}$ during this interval. Overall, these results are thus compatible with the simple estimate made in the introduction that the phase speed associated with flow pattern expansion away from the noon sector should be of 
the order of several kilometres per second. The results are also consistent with the only previous direct measurement of dayside convection pattern phase speed: the $2.6 \mathrm{~km} \mathrm{~s}^{-1}$ eastward value obtained by Lockwood et al. [1986] in the postnoon sector.

\section{VARIATIONS IN THE IONOSPHERIC RESPONSE TIME}

If the ground magnetic perturbations are due principally to variations in the ionospheric plasma flow driven by magnetic reconnection at the magnetopause, then the ground disturbance should be correlated with IMF $B_{2}$ with a response delay time which varies in local time in a manner compatible with the above determined longitudinal phase motions about the prenoon sector. The results of cross-correlating IMF $B_{z}$ with the $Y$ component of the ground magnetic disturbance observed at CONT and RANK are shown in Figure 5. A sliding 2-hour window was used with cross correlation functions computed every half hour. Results for RANK are shown displaced slightly to the left of each half hour of MLT, while those for CONT are displaced slightly to the right. The level of correlation is indicated by the shading code defined at the top left of the figure. Even cross correlations as low as 0.25 imply reliable time lags, for their significance levels are much greater than $99 \%$ [Fisher, 1948], due to the large number of pairs of points (1437) used in computing each correlation. The ionospheric response time is plotted as the ordinate and is shown after subtracting $13 \mathrm{~min}$ from the computed time lag, this representing our best estimate of the time required for the IMF "signal" to propagate from IMP 8 to the noon sector ionosphere (as discussed earlier).

Figure 5 suggests a trend in response times with shorter delays of - 5 min occurring in the prenoon sector at 8-12 MLT, and longer

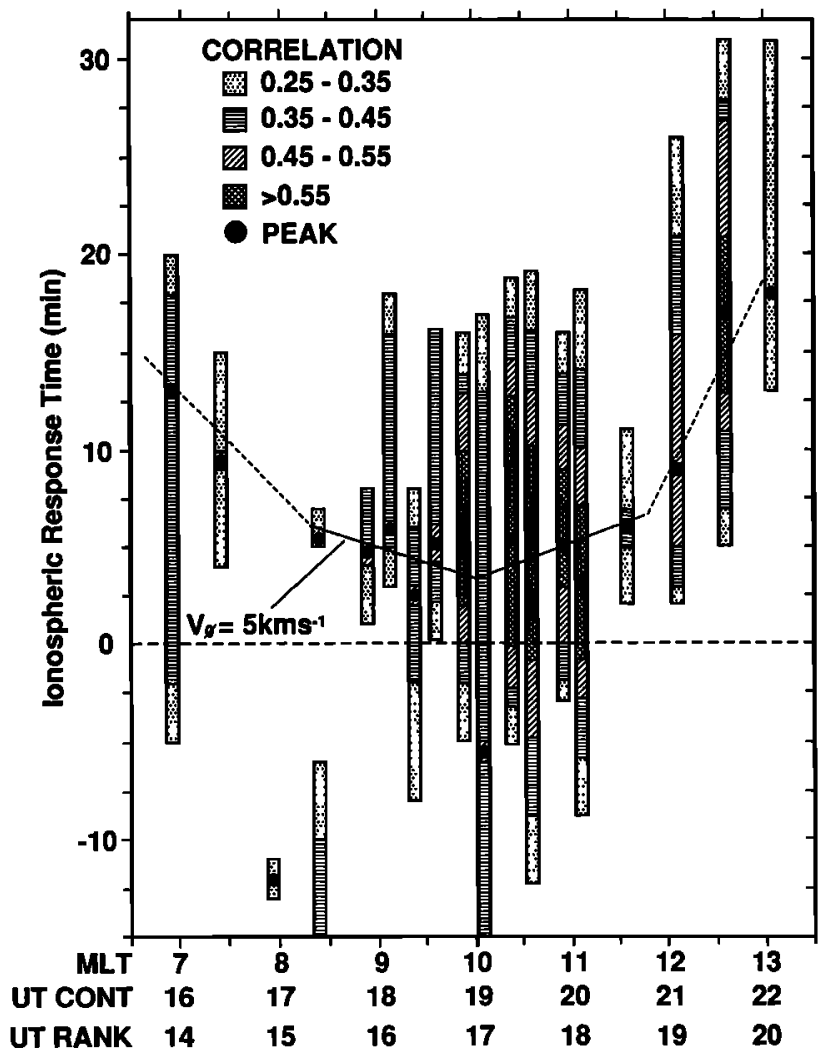

Fig. 5. Results of cross-correlating IMF $B_{z}$ and ground $B_{Y}$ data to give the ionospheric response time as a function of MLT. Two correlation results are presented at each half hour of MLT, the left-hand value being that between IMF $B_{z}$ and CONT $B_{Y}$, and the right-hand value being that between IMF $B_{z}$ and RANK $B$. delays of $\sim 10-15 \mathrm{~min}$ being observed in the regions 1-2 hours on either side. The response time variation expected for a propagation speed of $5 \mathrm{~km} \mathrm{~s}^{-1}$ away from 10 MLT over the 8-12 MLT interval is shown by the superposed solid lines. Within their uncertainty the results in Figure 5 are clearly compatible with the phase propagation speeds derived directly from the two-station cross correlations presented in Figure 4. At earlier and later local times the dashed lines indicate the variation expected in the response time for slower phase speeds of 0.7 and $1.3 \mathrm{~km} \mathrm{~s}^{-1}$ respectively, values again compatible with the two-station results obtained later in the interval in Figure 4. The results shown in Figure 5 are very similar to those derived previously by Etemadi et al. [1988] and by Todd et al. [1988] using the EISCAT-AMPTE data set. However, in their study the minimum in the response time was just postnoon ( 1330 MLT; see Lockwood and Cowley [1988], rather than prenoon ( 10 MLT) as found here. The reason for this difference is unclear. It does not appear to result from the effect of IMF $B Y$, since the latter is generally positive during the intervals of negative IMF $B_{2}$ (Figure 1). For reconnection-driven ionospheric flow in the northem hemisphere, positive IMF $B_{Y}$ favors the displacement of plasma flow initiation toward postnoon rather than prenoon [e.g., Heppner and Maynard, 1987].

\section{INTER PRETATION}

Figures 6 and 7 present schematic diagrams indicating our interpretation of the above results. Figure 6 shows the expected dayside ionospheric polar flow pattern at two times, separated by $\sim 5$ min, shortly after a sudden southward tuming of the IMF $B_{z}$ component impacts the magnetopause. The initiation of reconnection at the magnetopause results in the equatorward motion of the open/closed field line boundary mapping to the reconnection $\mathrm{X}$ line (heavy solid line in the figure), followed by the excitation of

a)

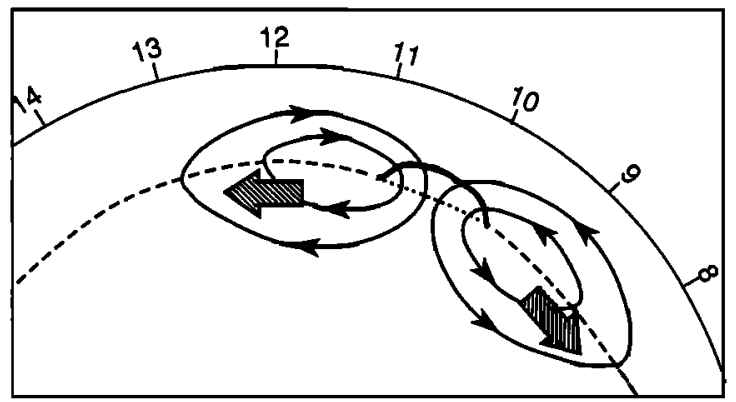

b)
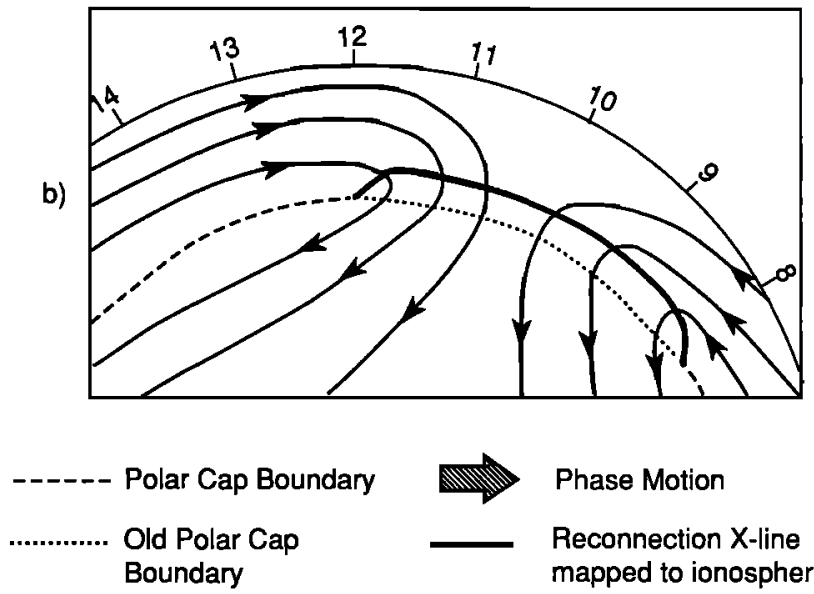

Phase Motion

Reconnection X-line mapped to ionosphere

Fig. 6. The onset and rapid expansion of plasma flows in the polar dayside ionosphere expected from the commencement of magnetic reconnection at the dayside magnetopause. 
a)

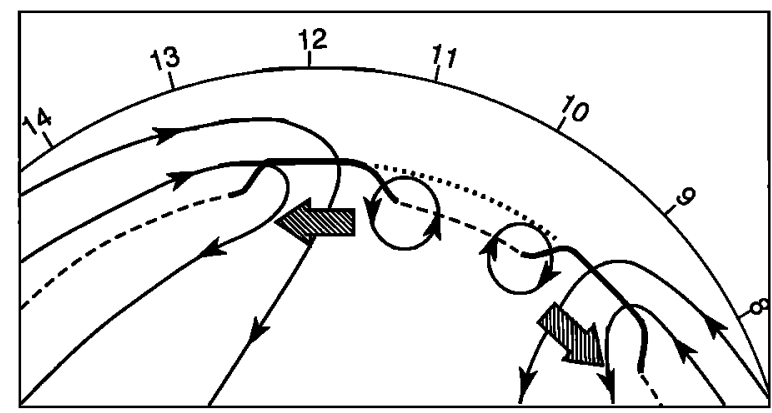

b)

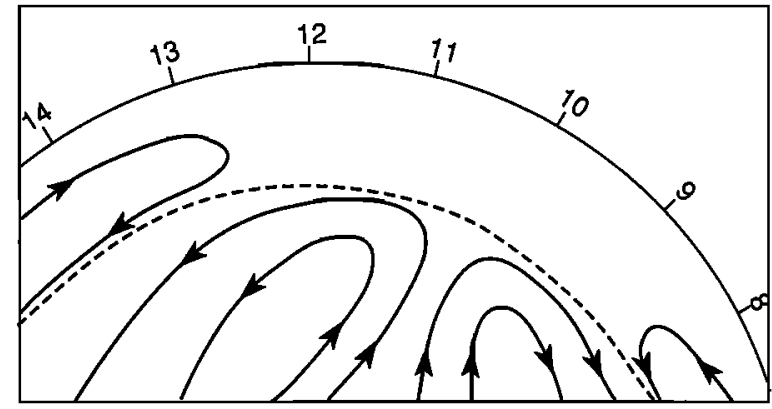

- - - Polar Cap Boundary

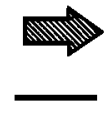

Phase Motion

Old Polar Cap

Reconnection X-line Boundary mapped to ionosphere

Fig. 7. (a) The decay of polar ionospheric plasma flows expanding away from the noon sector expected to follow a northward tuming of the IMF impinging upon the magnetopause and $(b)$ a possible scenario for sunward plasma flows during intervals of steady northward IMF.

a twin-vortical flow. Initially the flow is confined to the vicinity of the mapped $X$ line (Figure $6 a$ ), but subsequently it expands outward (Figure $6 b$ ) with a phase speed of $\sim 5 \mathrm{~km} \mathrm{~s}^{-1}$. This phase expansion occurs both as a result of the reconnection $X$ line spreading over the magnetopause, and as the response to the reconnection spreads through the magnetosphere-ionosphere system. Subsequent variations in the magnetopause reconnection rate will also give rise to phase motion away from the site of the initial change. Indecd the 1530 UT to 1615 UT interval in Figure 4 suggests that this behavior applies to all variations with periods from $\sim 10 \mathrm{~min}$ upward.

The major flow perturbation in Figure $6 a$ is associated with the regions of poleward plasma flow. The equatorward flow on the leading edges of the expanding twin vortices is considerably weaker and, for stations in the throat region, would be observable at any one site for only about a minute following the initiation of reconnection. Thus the leading edges of the twin vortices are not expected to produce significant signals on the ground in this region. However, for stations outside that region one might see a weak equatorward flow component associated with the expansion of the polar cap [Siscoe and Huang, 1985]. The vortical flow patterns also have clear implications for the expected $X-Y$ plane polarization pattems in the ground magnetometer signals. This polarization should vary with latitude and reverse sense about the site of initial change ( 10 MLT). Detailed examination of the $X-Y$ plane polarization will be a topic for future study but initial work suggests it to be largely linear, indicating CANOPUS station locations close to the polar cap boundary. A final feature of note is that the minimum response delay in Figure 5 is $\sim 5 \mathrm{~min}$ rather than zero. This suggests either that changes in the reconnection rate are substantially delayed at the magnetopause before spreading in local time, for which we know of no explanation, or that our "best" estimate of the IMP 8-to-ground propagation delay (13 $\mathrm{min}$ ) is in error by a small margin.

Our results also indicate that flow reductions following northward tumings of the IMF are initiated in the prenoon sector before spreading rapidly in local time, a result in agreement with the findings of Todd et al. [1988]. As indicated in Figure $7 a$ we envisage a cessation of reconnection spreading outward from an initial central point giving rise to corresponding effects in the ionospheric flow. This figure represents the situation $3 \mathrm{~min}$ after the initiation of this process, and indicates the possible existence of a weak equatorward flow in the region between the now separated and contracting reconnection regions. A similar flow pattern has been drawn by Southwood [1987], but in the context of two spatially separated flux transfer events. This equatorward flow will, however, only be present during the $\sim 5$ - to $\sim 10$-min interval which it takes the twin-vortical flow to die away.

Earlier we commented that the deflections in the $Y$ component ground magnetic disturbances (within the uncertainties of their absolute baselines) may indicate the presence of continuous equatorward flows in the prenoon sector during the intervals of strongly northward IMF $B_{z}$. If this is the case we would infer the existence of sunward flows in the polar cap driven by reconnection at the tail lobe magnetopause as discussed in the introduction and illustrated in Figure $7 b$. The observation of sunward flows at these latitudes would be unusual [Elemadi et al., 1988] but not perhaps unreasonable considering that the large positive excursions of IMF $B_{z}$ follow on from the large negative excursions, the latter implying a substantially expanded polar cap, at least during the initial period of positive $B_{z}$. A further example of sunward flows driven by positive IMF $B_{\mathbf{z}}$ being observed at a relatively low latitude on the dayside may be found in the work of Knipp et al. [1991].

\section{CONCLUSIONS}

How polar ionospheric plasma flows reconfigure following the onset or decay of dayside magnetopause reconnection is a topic of much interest to studies of magnetosphere-ionosphere coupling. A parameter central to this question is the longitudinal phase motion with which perturbations to the flow pattern expand away from the noon sector. Prior to our study only one direct measurement of this phase speed has been made (that by Lockwood et al. [1986]), and two indirect measurements (those by Elemadi et al. [1988] and by Todd et al. [1988]). Here we make a continuous assessment of this east-west phase propagation speed over the 6 hour MLT range between 7 and 13 hours. Two independent approaches are employed which give compatible results. The first involves cross-correlating signals from two ground magnetometer stations situated at $73.5^{\circ}$ magnetic latitude and separated by $\sim 2$ hours in MLT; the second involves cross-correlating records from these same stations with IMF $B_{\mathbf{z}}$ to confirm that the ionospheric signals are related to the IMF and to determine how the ionospheric response varies with longitudinal position. We find that the ground signals exhibit phase motion away from $10 \mathrm{MLT}$ toward dawn or dusk, initially at a speed of $5 \mathrm{~km} \mathrm{~s}^{-1}$ but slowing to $2 \mathrm{~km} \mathrm{~s}^{-1}$ or less at MLT displacements of 2 hours or more. We interpret the observations in terms of the plasma flow excited by the onset, expansion and decay of magnetic reconnection at the dayside magnetopause. The $5 \mathrm{~km} \mathrm{~s}^{-1}$ value agrees with simple estimates for the expansion speed of a flow pattern in the magnetosphere-ionosphere system.

Acknowledgments. This work was performed while one of us (M.A.S.) was supported by a Royal Society 1983 Research Fellowship, and while another (M.P.F.) was funded by a SERC postdoctoral research award. C.J.F. thanks the Universities Space Research Association for financial support. The 
CANOPUS magnetometer array was constructed, and is maintained and operated, by the Canadian Space Agency for the Canadian Scientific community. We thank N. Powell for help in preparing the figures.

The Editor thanks E.Sandholt and another referee for their assistance in evaluating this paper.

\section{REFERENCES}

Atkinson, G., Magnetospheric flows and substorms, in MagnetosphereIonosphere Interactions, edited by K. Folkestad, p. 203, Universitetsforlaget, Oslo, Norway, 1972.

Baker, D. N., E. W. Hones, Jr., J. B. Payne, and W. C. Feldman, A hightime resolution study of interplanetary parameter correlations with $A E$, Geophys. Res. Lett., 8, 179-182, 1981.

Baker, D. N., R .D. Zwickl, S. J. Bame, E. W. Hones, Jr., B. T. Tsurutani, E J. Smith, and S. I. Akasofu, An ISEE-3 high time resolution study of interplanetary parameter correlations with magnetospheric activity, J.Geophys. Res., 88, 6230-6242, 1983.

Bargatze, L. F., D. N. Baker, R. L. McPherron, and E. W. Hones, Jr., Magnetospheric impulse response for many levels of geomagnetic activity, J.Geophys. Res., 90, 6387-6394, 1985a.

Bargatze, L. F., D. N. Baker, and R. L. McPherron, Superposed epoch analysis of magnetospheric substorms using solar wind, auroral zone and geostationary orbit datasets, in Magnetotail Physics, edited by A. T. Y. Lui, pp.163-168, The Johns Hopkins University Press, Baltimore, Md., $1985 b$.

Berchem, J., and C. T. Russell, Flux transfer events on the magnetopause: Spatial distribution and controlling factors, J. Geophys. Res., 89, 6689 6704,1984

Burke, W. J., M. C. Kelley, R. C. Sagalyn, M. Smiddy, and S. T. Lai, Polar cap electric field structures with a northward interplanetary magnetic field, Geophys. Res. Lett., 6, 21-24, 1979.

Clauer, C. R., and E. Friis-Christensen, High-latitude dayside electric fields and currents during strong northward interplanetary magnetic field: $\mathrm{Ob}-$ servations and model simulation, J. Geophys. Res., 93, 2749-2757, 1988.

Clauer, C. R., and Y. Kamide, DP1 and DP2 current systems for the March 22, 1979 substorms, J. Geophys. Res., 90, 1343-1354, 1985.

Cowley, S. W. H., Magnetospheric asymmetries associated with the $Y$ component of the IMF, Planet. Space Sci., 29, 79-96, 1981.

Cowley, S. W. H., Interpretation of observed relations between solar wind characteristics and effects at ionospheric altitudes, in High Latitude Space Plasma Physics, edited by B. Hultqvist and T. Hagfors, p. 225, Plenum, New York, 1983.

Cowley, S. W. H., and M. Lockwood, Excitation and decay of solar winddriven flows in the magnetosphere-ionosphere system, Ann.Geophys., 10, 103-115, 1992.

Cowley, S. W. H., J. P. Morelli, and M. Lockwood, Dependence of convective flows and particle precipitation in the high latitude dayside ionosphere on the $X$ and $Y$ components of the interplanetary magnetic field, $J$. Geophys. Res., 96, 5557-5564, 1991.

Doyle, M. A., and W. J. Burke, S3-2 measurements of the polar cap potential, J. Geophys. Res., 88, 9125-9134, 1983.

Dungey, J. W., Interplanelary field and the auroral zones, Phys. Rev. Lett., $6,47-48,1961$.

Dungey, J. W., The structure of the ionosphere, or adventures in velocity space, in Geophysics: The Earth's Environment edited by C. DeWill, J. Hiebolt, and A. Lebeau, pp.526-536, Gordon and Breach, New York, 1963.

Etemadi, A., S.W.H.Cowley, M.Lockwood, B.J.I.Bromage, D.M.Willis, and H.Luhr, The dependence of high-latitude dayside ionospheric flows on the north-south component of the IMF: A high time resolution correlation analysis using EISCAT "Polar" and AMPTE UKS and IRM data, Planet. Space Sci., 36, 471-498, 1988

Fisher, R. A., Statistical Methods for Research Workers, 354pp., Oliver and Boyd, Edinburgh, 1948.

Friis-Christensen, E. and J. Wilhjelm, Polar cap currents for different directions of the interplanetary magnetic field in the $y-z$ plane, J. Geophys. Res., $80,1248-1260,1975$.

Gosling, J. T., M. F. Thomsen, S. J. Bame, R. C. Elphic, and C. T. Russell, Observations of reconnection of interplanetary and lobe magnetic field lines at the high-latitude magnetopause, J. Geophys. Res., 96, 14,097$14,106,1991$.

Greenwald, R. A., K. B. Baker, J. M. Ruohoniemi, J. R. Dudeney, M. Pinnock, N. Mattin, J. M. Leonard, and R. P. Lepping, Simultaneous conjugate observations of dynamic variations in high-latitude dayside convection due to changes in IMF BY, J. Geophys. Res., 95, 8057-8072, 1990.

Hairston, M. R., and R. A. Heelis, Model of the high latitude ionospheric convection patlem during southward interplanetary magnetic field using DE 2 data, J. Geophys. Res., 95, 2333-2343, 1990.

Heppner, J. P., Polar cap electric field distributions related to the interplanetary electric field direction, J. Geophys. Res. 77, 4877-4887, 1972.

Heppner, J. P., High latitude electric fields and modulations related to interplanetary magnetic field parameters, Radio Sci., 8, 933-948, 1973.

Heppner, J. P., and N. C. Maynard, Empirical high-latitude electric field models, J. Geophys. Res., 92, 4467-4489, 1987.

Holt, J. M., R. H. Wand, J. V. Evans, and W. L. Oliver, Empirical models for the plasma convection at high latitudes from Millstone Hill observations, J. Geophys. Res., 92, 203-212, 1987.

Holzworth, R. H., and C.-I. Meng, Mathematical representation of the auroral oval, Geophys. Res. Lell., 2, 377-380, 1975.

Holzworth, R. H., and C.-I. Meng, Auroral boundary variations and the interplanetary magnetic field, Planet. Space Sci., 32, 25-29, 1984.

Hones, E. W., Jr., Plasma flow in the plasma sheet and its relation to substorms, Radio Sci., 8, 979-990, 1973.

Horwitz, J. L., and S.-I. Akasofu, The response of the dayside aurora to sharp northward and southward transitions of the interplanetary magnetic field and to magnetospheric substorms, J. Geophys. Res., 82, 2723-2734, 1977.

Jorgensen, T. S., E. Friis-Christensen, and J. Wilhjelm, Interplanetary magnetic field direction and high-latitude ionospheric currents, J. Geophys. Res., 77, 1976-1977, 1972.

Knipp, D. J., A. D. Richmond, B. Emery, N. U. Crooker, O. de la Beaujardiere, D. Evans, and H. Kroehl, Ionospheric convection response to changing IMF direction, Geophys. Res. Lett., 18, 721-724, 1991.

Lester, M., M. P. Freeman, D. J. Southwood, J. A. Waldock, and H. Singer, A study of the relationship between interplanetary parameters and large displacements of the nightside polar cap boundary, J. Geophys. Res., 95, 21,133-21,146, 1990.

Lockwood, M., and S. W. H. Cowley, Observations at the magnetopause and in the auroral ionosphere of momentum transfer from the solar wind, Adv. Space Res., 8, 281-299, 1988

Lockwood, M., and M. P. Freeman, Recent ionospheric observations relating to solar wind-magnetosphere coupling, Phil. Trans. R. Soc. London, Ser. A, 328, 93-105, 1989.

Lockwood, M., A. P. van Eyken, B. J. I. Bromage, D. M. Willis, and S. W. H. Cowley, Eastward convection of a plasma convection enhancement following a southward tuming of the interplanetary magnetic field, Geophys. Res. Lett., 13, 72-75, 1986.

Lockwood, M., S. W. H. Cowley, and M. P. Freeman, The excitation of plasma convection in the high-latitude ionosphere, J. Geophys. Res., 95 , 7961-7972, 1990 .

Maezawa, K., Magnetospheric convection induced by the positive and negative components of the interplanetary magnetic field: Quantitative analysis using polar cap magnetic records, J. Geophys. Res., 81, 2289$2303,1976$.

McDiarmid, I. B., J. R. Burrows, and M. D. Wilson, Comparison of magnetic field perturbations at high latitudes with charged particle and IMF measurements, J. Geophys. Res., 83, 681-688, $1978 a$.

McDiarmid, I. B., J. R. Burrows, and M. D. Wilson, Magnetic field perturbations in the dayside cleft and their relationship to the IMF, J. Geophys. Res., 83, 5753-5756, 19786 .

McPherron, R. L., and R. H. Manka, Dynamics of the 10.54 UT March 2 , 1979, substorm event: CDAW 6, J. Geophys. Res., 90, 1175-1190, 1985.

Nishida, A., Geomagnetic DP 2 fluctuations and associated magnetospheric phenomena, J. Geophys. Res. 73, 1795-1803, 1968 a.

Nishida, A., Coherence of geomagnetic DP 2 fluctuations with interplanetary magnetic variations, J. Geophys. Res., 73, 5549-5559, $1968 b$.

Nishida, A., and Y. Kamide, Magnetospheric processes preceding the onset of an isolated substorm: A case study of the March 31, 1978, substorm, $J$. Geophys. Res., 88, 7005-7014, 1983.

Paschmann, G., B. U. O. Sonnerup, I. Papamastorakis, N. Sckopke, G. Haerendel, S. J. Bame, J. R. Asbridge, J. T. Gosling, C. T. Russell, and R. C. Elphic, Plasma acceleration at the Earth's magnetopause: Evidence for reconnection, Nalure, 282, 243-246, 1979.

Paschmann, G., I. Papamastorakis, W. Baumjohann, N. Sckopke, C. W. Carlson, B. U. O. Sonnerup, and $\mathrm{H}$. Luhr, The magnetopause for large magnetic shear: AMPTE/IRM observations, J. Geophys. Res., 91, 11,099$11,115,1986$.

Pellinen, R. J., W. Baumjohann, W. J. Heikkila, V. A. Sergeev, A. G. Yahnin, G. Marklund, and A. Melnikov, Event study on pre-substorm 
phases and their relation to the energy coupling between the solar wind and the magnetosphere, Planet. Space Sci., 30, 371-388, 1982.

Reiff, P. H., Sunward convection in both polar caps, J. Geophys. Res., 87, 5976-5980, 1982.

Reiff, P. H., and J. G. Luhmann, Solar wind control of the polar cap voltage, in Solar Wind Magnetosphere Coupling, edited by Y. Kamide and J. A. Slavin, pp. 453-476, Terra Scientifica, Tokyo, 1986.

Reiff, P. H., R. W. Spiro, and T. W. Hill, Dependence of polar cap potential drop on interplanetary parameters, J. Geophys. Res., 86, 7639-7648, 1981.

Rijnbeek, R. P., S. W. H. Cowley, D. J. Southwood, and C. T. Russell, A survey of dayside flux transfer events observed by ISEE 1 and 2 magnetometers, J. Geophys. Res., 89, 786-800, 1984.

Rishbeth, H., P. R. Smith, S. W. H. Cowley, D. M. Willis, A. P. van Eyken, B. J. I. Bromage, and S. R. Crothers, Ionospheric response to changes in the interplanetary magnetic field observed by EISCAT and AMPTEUKS, Nature, 318, 451-452, 1985.

Russell, C. T., The configuration of the magnetosphere, in Critical Problems in Magnetospheric Physics, edited by E. R. Dyer, Jr., pp. 1-16, National Academy of Sciences, Washington D. C., 1972.

Russell, C. T., and R. L. McPherron, The magnetotail and substorms, Space Sci. Rev., 15, 205-266, 1973.

Siscoe, G. L., and T. S. Huang, Polar cap inflation and deflation, J. Geophys. Res., 90, 543-547, 1985.

Sonnerup, B. U. O., G. Paschmann, I. Papamastorakis, N. Sckopke, G. Haerendel, S. J. Bame, J. R. Asbridge, J. T. Gosling, and C. T. Russell, Evidence for magnetic field reconnection at the Earth's magnelopause, $J$. Geophys. Res., 86, 10,049-10,067, 1981.

Southwood, D. J., The ionospheric signature of flux transfer events, $J$. Geophys. Res., 92, 3207-3213, 1987.

Todd, H., B. J. I. Bromage, S. W. H. Cowley, M. Lockwood, A. P. van Eyken, and D. M. Willis, EISCAT observations of bursts of rapid flow in the high latitude dayside ionosphere, Geophys. Res. Lett., 13, 909-912, 1986.

Todd, H., S. W. H. Cowley, M. Lockwood, D. M. Willis, and H. Luhr, Response time of the high latitude dayside ionosphere to sudden changes in the north-south component of the IMF, Planet. Space Sci., 36, 1415$1428,1988$.

Vorobjev, V. G., G. V. Starkov, and Y. I. Feldstein, The auroral oval during substorm development, Planet. Space Sci., 24, 955-966, 1976.

Wygant, J. R., R. B. Torbert, and F.S. Mozer, Comparison of S3-3 polar cap potential drops with the interplanclary magnelic field and models of magnetopause reconnection, J. Geophys. Res., 88, 5727-5735, 1983.

S. W. H. Cowley, M. A. Saunders and D. J. Southwood, Blackett Laboratory, Imperial College of Science, Technology and Medicine, London SW7 2BZ, United Kingdom.

C. J. Farrugia, Code 692, NASA/Goddard Space Flight Center, Greenbelt, MD 20771.

M. P. Freeman, Upper Atmospheric Science Division, British Antarctic Survey, Madingley Road, Cambridge CB3 OET, United Kingdom.

T. J. Hughes, Herzberg Institute of Astrophysics, National Research Council of Canada, Ottawa, Ontario, Canada K1 A OR6.

M. Lockwood, Rutherford Appleton Laboratory, Chilton, Didcot, Oxon. OX11 0QX, United Kingdom.

J. C. Samson, Canadian Network for Space Research, Physics Department, University of Alberta, Edmonton, Alberta, Canada T6G 2J1.

(Received February 24, 1992;

revised May 20, 1992;

accepted May 25, 1992.) 